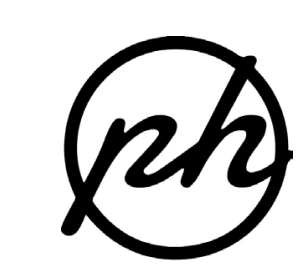

ESTUDIOS LITERARIOS

\title{
ALGUNOS APUNTES SOBRE FOLKLORE Y ESPACIO EN LA TRADICIÓN ORAL DE BORMUJOS (SEVILLA) ${ }^{1}$
}

FOLKLORE AND SPACE IN THE ORAL TRADITION OF BORMUJOS (SEVILLA)

\author{
Adriano DuQue \\ Villanova University \\ adriano.duque@villanova.edu
}

\begin{abstract}
RESUMEN
Situada a escasos siete kilómetros de la ciudad de Sevilla, la población de Bormujos figura ya desde el repartimiento de 1267 como una localidad eminentemente agraria, dominada por su situación como lugar de paso entre Castilleja de la Cuesta y Almensilla. El desarrollo de esta actividad agraria y las relaciones con las poblaciones vecinas ha determinado el desarrollo de una tradición oral en las coplas, a menudo breves, con las que medían el tiempo de sus festividades y labores agrícolas. Las explicaciones de los informantes reflejan por otro lado una concepción especial del espacio urbano que depende íntimamente de la memoria oral.
\end{abstract}

Palabras clave: Bormujos, folklore, espacio, tradición oral, tradición popular.

\begin{abstract}
Located just seven kilometers away from the city of Sevilla, Bormujos appears already in 1267 as a largely agrarian population, dominated by its status as a transit way between the towns of Castilleja de la Cuesta and Almensilla. The development of this agricultural activity and relations with neighboring populations have determined the development of an oral tradition in couplets, often brief, that allowed people to measure their leisure time and their agricultural chores. Explanations of the different informants reflect on the other hand a special conception of urban space stemming from oral memory.
\end{abstract}

Keywords: Bormujos, folklore, space, oral tradition, popular tradition.

\footnotetext{
${ }^{1}$ Debo mi agradecimiento a Félix Cortés Vázquez, a Baldomero Gordillo Polvillo y muy en especial a Marta Palenque, por sus sugerencias e indicaciones al componer este trabajo.
} 


\section{INTRODUCCIÓN}

En un ensayo reciente sobre tradiciones populares, William Moylan destaca cómo la idea de espacio constituye un elemento fundamental dentro de la transmisión musical. En la medida en que la música se adapta y se presenta a la audiencia, la canción genera diferentes tipos de percepción social que varían según el lugar y el momento en el que se transmite. En este sentido, afirma Moylan, "the two levels of middle and large dimension serve as meaningful references for the study of spatial relationships in recorded music, as they dominate the listener's conception of the music recording and are the materials directly crafted in production practice" (Moylan 2012: 67). De acuerdo con esta idea, el espacio físico que se describe en las canciones populares refleja el contexto vivo de la historia que produce el evento, y evoca los términos de ese mismo espacio social (Gunnell 2006: 7).

La publicación de los trabajos de Terry Gunnel o Lauri Honko sobre el papel del espacio dentro de la tradición folklórica han permitido descartar la simple reproducción de los testimonios folklóricos y favorecer una perspectiva que permita considerar las canciones dentro de un contexto social compuesto por toda una serie de símbolos, sonidos y palabras. La idea del espacio como elemento transmisor de tradiciones folklóricas expresa la visión especial que el informante tiene del espacio que lo rodea (Gunnell 2006: 7). Sea ya en la misma letra o en las explicaciones que el hablante da de las circunstancias en que aprendió o se ejecutaban las canciones, la percepción del espacio en las canciones tradicionales se asocia íntimamente con la creación de un espacio comunitario, con la reproducción de una serie de elementos que comparten el informante y su audiencia (Gunnell 2006: 8).

Las páginas que siguen se centran en la tradición oral de un pueblo del Aljarafe sevillano: Bormujos. Las canciones fueron recogidas en una campaña de recolección de canciones llevada a cabo en el casco urbano de Bormujos (Sevilla) entre los 2009 y 2011, junto con Baldomero Gordillo Polvillo. La selección de canciones se ha realizado sobre la base de la taxonomía de tradiciones orales establecida por James Foley, para quien la poesía oral comprende no sólo aquellas canciones transmitidas por vía oral sino también aquellas que se hallan recogidas por escrito (Maxey 2009: 97). Esto ocurre por ejemplo con varias coplas de bamba que si bien fueron cantadas en su día por la Niña de los Peines (189o-1969), se han transmitido como parte de la tradición oral.

Tomando como punto de partida su situación geográfica en el perímetro suburbano de la ciudad de Sevilla, mi estudio se propone examinar cómo es que las diferentes canciones crean un espacio físico-temporal capaz de evocar y de generar nuevas visiones del ámbito urbano destinadas no sólo a expresar las emociones e inquietudes de cada individuo sino además a involucrar al oyente (Huizinga 1949: 13). Desde este punto de vista, el trabajo parte de la idea de que el espacio no existe en sí mismo sino que depende de una percepción íntima del tiempo expresada en las tradiciones populares (Honko 1990: 547). Aun a pesar de la explosión demográfica 
de los últimos años, ${ }^{2}$ la tradición oral sigue evocando un espacio urbano mítico, de difícil periodización.

Según testimonio de los diferentes informantes, la vía principal de acceso discurría por la actual Calle de Nuestra Señora de los Dolores, que discurre desde el cementerio a la iglesia de Nuestra Señora de la Encarnación, pasando por la hacienda de Ntra. Sra. de Belén y la Atarazana. En el siglo XIX, la nueva carretera a Villamanrique comunicó el pueblo directamente con Bollullos de la Mitación, desviando también el centro del pueblo hacia la carretera principal. Todavía en los años sesenta, la calle principal se conocía como la "calle del Congo". Hacia mediados del siglo XX, el pueblo se dividía en cuatro barrios, delimitados al oeste por el arroyo del Almage: las Cochineras (cerca del cementerio de Santo Domingo), ${ }^{3}$ Maclica (por la plaza de José Moreno), la Cruz, el Barrero (que había sido finca de don Manuel Piñal $)^{4}$ y el Prado. Según explican varios de los informantes, el centro de la población se encontraba en la plaza del Cañón (junto a la hacienda de Ntra. Sra. de Belén) y en la calle Sevilla. Ahí era al menos donde paraban los "copleros" que venían de otras poblaciones. ${ }^{5}$

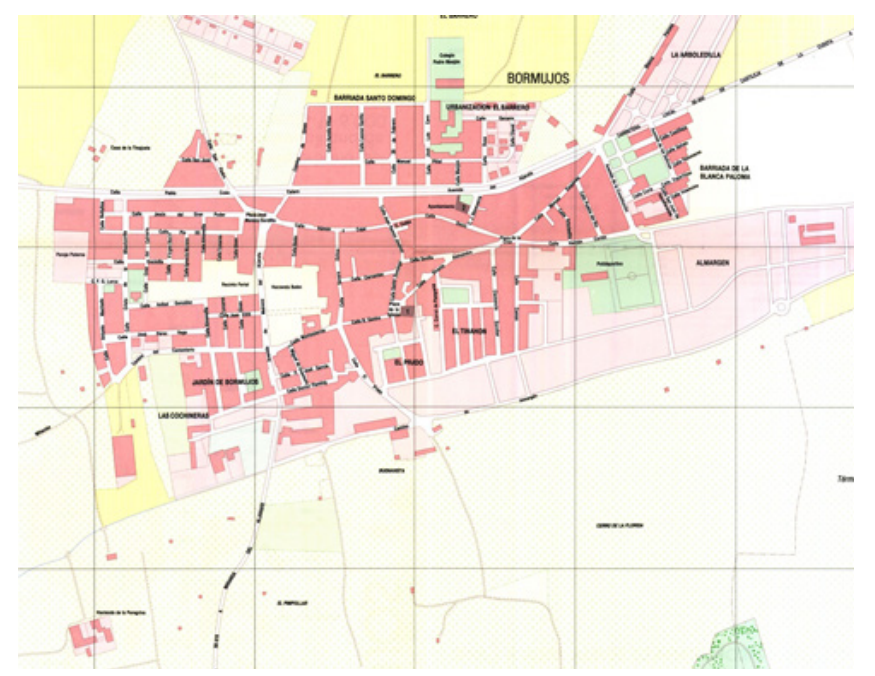

Figura 1: Plano de Bormujos (1992). Cartografía urbana del territorio de Sevilla. Excmo. Ayuntamiento de Bormujos.

${ }^{2}$ La población pasó de 1.339 habitantes en 1900 a 21.362 en 2007. Fuente: Instituto nacional de estadística.

3 Paco Ortega menciona que en las Cochineras era donde se cogía la borra del aceite para hacer jabón. http://pakortega.blogspot.com.es (5 agosto 2009).

4 Manuel Piñal, agricultor y automovilista, propietario de La Peregrina, fue guía del rey Alfonso XIII con motivo de su visita al pueblo en 1921 (ABC, 11 marzo 1921).

5 Paco Ortega refiere que muchas de las representaciones se hacían en la Plazoleta del Cano, y recuerda a un juglar inválido de manos, que perdía la invalidez tan pronto salía del pueblo. También recuerda a los trileros http://pakortega.blogspot.com.es/ (30 octubre 2009).

ISSN $1132-0265$ 


\section{Procesos de Ritualización: CANCiones de baMba}

Dentro de la tradición oral de Bormujos, las canciones evocan una serie de actividades y de lugares físicos sobre los que se articula una visión paradigmática de la sociedad del pueblo. Al evocar el universo de la canción, el ritual adapta las imágenes del pasado a un nuevo contexto y sanciona una serie de comportamientos sociales que se transmiten de generación en generación (Foley 2002: 6; Finnegan 1977: 251). El lugar y las circunstancias en torno a las que se desarrolla la bamba se transforman en un lugar de memoria, en un espacio sobre el que proyectar la percepción del espacio físico (Zumthor 1983: 245). Una vez que la audiencia reconoce la relación entre ese pasado y el momento presente, la canción puede desarrollarse (Gunnell 2006: 13).

La ritualización del pasado adquiere un significado especial en las canciones de bamba, un tipo especial de canciones que se cantaba con ocasión de las fiestas del pueblo. El origen de la canción de bamba remonta al siglo XIX y se muestra ya en relatos como La venta de los gatos (1862) de Gustavo Adolfo Bécquer (Penna 1969). En Los majos de Cádiz (1896), Armando Palacio Valdés describe también una bamba en los corrales de las tiendas de Cádiz, colocada entre los meses de diciembre y febrero (desde Navidad hasta Carnaval), y recoge algunas de las coplas que se cantaban, todas con doble sentido (Palacio 1967: 80). Andrés Raya por su parte atribuye el descubrimiento de la canción de bamba a Pepe Pinto, esposo de la Niña de los Peines, quien las grabó por vez primera en 1949 con acompañamiento de Melchor de Marchena. Aun cuando la mayoría de las canciones de bamba de Bormujos se componen de cuatro versos, Andrés Raya afirma que el origen de la canción de bamba estaba no en la cuarteta sino en la quintilla de versos octosílabos (Raya 2014). ${ }^{6}$

Según explican los informantes, la bamba consistía en un columpio que se colocaba de un olivo (Esperanza Hernández Tejera, 71 años) en alguno de los corrales del pueblo. Para las más grandes se armaban dos vigas y una atravesada y se apuntalaba con sacos. Durante la feria, se solía colocar un columpio en el corral de la Pampana. ${ }^{7}$ Otras bambas se colocaban en el corral de Dominga la Basurera, en la carretera nueva. Según Isabel Vázquez (65 años), la bamba se ponía en la venta Luque y se montaban principalmente las mujeres y las chiquillas. Se podían pagar tres perras chicas, o una gorda. Para medir el tiempo, se cantaban tres canciones y al terminar, se cambiaba de persona. Según Rosario Acevedo Miralles (84 años), la bamba se celebraba también en las fiestas de Carnaval. Según Francisco León

6 Cf. Bohórquez 20oo: 141; Ruiz et al. 1988: 23. V. también Carmen Durán Medina (1999) y El Cancionerillo de Aznalcázar. Aproximación a la bamba. Romances y Canciones en la Tradición Andaluza. Ed. Pedro Piñero, Enrique Baltanás y J. Pérez Castellano. María Jesús Ruiz relaciona a su vez la bamba con la tradición de los meceores que se ponían durante la noche del domingo de Resurrección. (María Jesús Ruiz et al. 2008: 13)

7 Paco Ortega sitúa en él "las cunitas o voladoras". http://pakortega.blogspot.com.es/ (25 octubre 2009). 
Gómez (71 años), durante el Carnaval se vendían dulces en la calle. Félix Cortés Vázquez señala como los hombres se vestían de mujer e iban dando sustos por el pueblo, especialmente por la calle Sevilla:

La bamba se ponía en la venta Luque. Se ponía un saco a modo de asiento. Cuando se acababa la Cuaresma, colgaban del columpio unos pantalones rellenos de paja (el Judas) y le pegaban palos. Las bamberas se cantaban cuando se ponían las bambas. Las bambas se hacían en Carnaval. Nos vestíamos con unas enaguas blancas el domingo de Piñata y a cantar y divertirse. Las chiquillas más que ná (Félix Cortés Vázquez, 69 años).

Como norma general, las bamberas tienden a evocar un contraste entre objetos y personas que se encuentran a diferentes alturas. El interlocutor se sitúa siempre en un plano inferior y se dirije a la mujer que está en lo alto del columpio, evocando una diferencia que a menudo justifica la interpelación. Dentro de este tipo de canciones, la tradición de Bormujos distingue dos grupos: las canciones adaptadas de otros juegos y las canciones de bamba transmitidas por cantaores como la Niña de los Peines (1890-1969). Entre las canciones adaptadas se encuentran la que dice "Al cementerio subí", adaptada de una canción de comba murciana (Guerrero 1996: 118). Entre las canciones de bamba, se reconocen varias adaptaciones de canciones populares como son "Ay qué ventana tan alta", ${ }^{8}$ " "Yo no voy a la marina". 9

Al cementerio subí
Con sangre puse un letrero
Arriba puse María $($ u otra $)$
Y abajo lo que te quiero. ${ }^{10}$
[Félix Cortés Vázquez, 69 años, 1 de setiembre 2009]

$* * *$

Ay qué ventana tan alta,

Ay qué balcón tan dorado;

Qué pena la de María,

Que su novio la ha dejado. ${ }^{11}$

[Félix Cortés Vázquez, 69 años, 1 de setiembre 20o9]

$* * *$

8 Procedente de otra copla:"Ay qué ventana tan alta,/ ay qué balcón tan dorado,/ ay qué niña tan bonita/ quién será su enamorado" (Cantos 1882: 134).

9 Esta copla proviene de otra más conocida: El cochecito lerén (Pedrosa et al. 2007: 62).

10 Guerrero Ruiz recoge la misma letra como parte de una canción en la tradición de Murcia. La canción concluye: “iAy! Qué ventana tan alta,/ jay! Que balcón tan florido./ Qué lástima de mí/ que el novio no me ha querido" (Guerrero 1996: 119).

${ }^{11}$ Ver nota anterior. La canción aparece recogida por Rodríguez Marín (Cantos 1882: 134.) 
Yo no voy a la marina, porque me quieren pegar.

Los muchachos d'la marina

Me la tienen sentenciá. ${ }^{12}$

[Félix Cortés Vázquez, 69 años, , 1 de setiembre 20o9]

Otras coplas de bamba parecen proceder directamente del repertorio flamenco. Es el caso de la copla "Allá arribita arribita," que la Niña de los Peines grabó en 1950 con Melchor de Marchena (Bohórquez 200o: 141). Otra de las copa de aquella grabación fue la que dice "Eres una y eres dos", que los informantes de Bormujos perciben como canción independiente:

Allá arribita arribita

Hay una pila de oro

Donde lavan las mocitas

Los pañuelos de los novios. ${ }^{13}$

$* * *$

La más chica la mayor y el estrechón.

Y un poquito más,

Para que la chica no llore más. ${ }^{14}$

[Isabel Vázquez, 65 años, 30 de agosto 20o9]

Eres una y eres dos,

Eres tres y eres cincuenta.

Eres la iglesia mayor

Donde toíto el mundo entra

Menos yo. ${ }^{15}$

[Rosario Avecedo, 84 años, 29 de agosto 2009]

${ }^{12}$ Existe una versión de esta canción en Prado del Rey (Cádiz), si bien en esta ocasión se trata de una canción de comba. La canción comienza por los versos "En Torregorda/ cayó un cañón" (Pérez y Martínez 2005: 23). Aquilino Duque (79 años) (79 años) recoge una versión diferente: "Yo no voy al Altozano/ porque me quieren pegar./ Los chavales de aquel barrio / me la tienen sentenciá."

${ }^{13}$ La canción aparece también en Espartinas, Bollullos de la Mitación y Aznalcázar (López Sánchez 2003: 110). Pedro Piñero documenta numerosos ejemplos en la tradición peninsular y reconoce en ella "connotaciones eróticas clamorosas" (Piñero 2004, 491).

${ }^{14}$ Esperanza Hernández Tejera, 71 años: "La más chica/ La más grande/ Las más requetegrande/ La mayor/Y el estrechón/ Son son".

15 Luis López Ruiz clasifica esta canción como canción folklórica aflamencada (López 2009: 43). Narciso Alonso Cortés lo clasifica como cantar popular de Castilla (Alonso 1914: 284). Para un estudio sobre la relación entre canción tradicional y flamenco, v. Luis Súarez Álvarez (1989). En relación con esta última canción, Félix Cortés menciona una bambera que repite los mismos motivos: "Una Carmen y otra Carmen/Y otra Carmen que son tres/Caramba con tanta Carmen/ Un convento voy a poner/ De la religión del Carmen./ Corre Bartolo que te coge el toro". Félix Cortés Vázquez, 69 años, 1 de septiembre 2009. La misma canción se halla recojida en Lanjarón (Gutiérrez Padial 1982: 154).

ISSN $1132-0265$

DOI 10.12795/PH2016.i3o.21

Philologia Hispalensis 30/2 (2016) 81-105 
A su vez, la adopción de la copla "Allá arribita arribita" da lugar a una versión burlesca. Esta interpreación refleja una preocupación por el contacto físico. Al igual que en las otras canciones de bamba, el lugar superior es visto como un lugar de peligro que el interlocutor debe evitar. La enfermedad de la niña en la bamba se asocia con el comercio ilícito con un individuo:
Allí arriba arribita
Hay un pollo con viruelas,
Otro más con sarampión,
Y otro con dolor de muelas. ${ }^{16}$
[Rosario Avecedo, 84 años, 29 de agosto 20o9]

Frente a las canciones de tono burlesco, la tradición reconoce otro tipo de canciones que se centran en el motivo sexual como expresión de una desigualdad social entre el hombre y la mujer. Desde este punto de vista, la imagen de un zapatero remendón desplaza la imagen de la niña que está en la bamba. Sin entrar en detalles, la imagen de un zapatero sentado en el tejado recuerda por otro lado el motivo de canciones populares como la de "Estaba el señor don Gato", expresión a su vez de las canciones de escarnio o cencerradas que se cantaban cuando el matrimonio entre dos personas era desigual o tardío: ${ }^{17}$

Aprieta bien los cordeles

Y arremonta en el tejado,

Que ahí verás

Un zapatero sentado

Sin tabaco y sin dinero. ${ }^{18}$

[Rosario Avecedo, 84 años, 29 de agosto 20o9]

El niño zangolotino

Puesto en el columpio va,

Y se le ha salido la tripa

con el calavar. ${ }^{19}$

[Rosario Avecedo, 84 años, 29 de agosto 20o9]

16 López Sánchez recoge la misma canción en Gines y Tomares (López Sánchez 2003: 104).V. Pedro Piñero (2010: 573).

${ }^{17}$ La figura del zapatero avaro es un motivo frecuente en los cuentos populares de Castilla y León (Macedonio 1987:313).V. El artículo de próxima aparición: Felipe Muñoz y Adriano Duque, "La canción de don Gato como cencerrada en las tradiciones europeas y americana".

${ }_{18}$ El verso "aprieta bien los cordeles" aparece en no pocas coplas de presos camino de la cárcel. La figura del zapatero sin dinero evoca la situación de penuria del hombre con el que la mujer va a juntarse (Fernández Molina p. 286). La alusión al tejado evoca la visibilidad de la novia. Cf. La canción del Señor Don Gato, donde un gato viejo se casa con una gata joven.

19 López Sánchez recoge otra versión de Aznalcázar: "La niña zangolotina/puesta en el columpio está/ quiera Dios que le seque/ la tripa del cagalá" (López Sánchez 2003: 99). 
Otras canciones indican la exposición pública de la mujer en el columpio, y se convierten en coplas de advertencia. Si consideramos el acto de montar en la bamba como un acto de socialización femenina, el propio lugar de la acción se convierte en un lugar de exhibición pública donde las acciones de la mujer se someten al escrutinio público. Desde este punto de vista, el doble sentido al que aludía Armando Palacio Valdés (v. Supra) se resuelve como una advertencia moral contras las cualidades físicas de la moza, su inocencia, o sus obligaciones familiares.

Esa que va en la bamba

Tiene la cara muy bonita...

(incompleto) ${ }^{20}$

[Eusebio Garrido Caro, 74 años, 1 de septiembre 20o9]

La niña que va a la bamba

se le cayó el abanico,

y ahora se va a abanicar

con el rabo del borrico. ${ }^{21}$

[Andrés Ruiz Moreno, Bormujos. 8o años, 29 de agosto 2009.]

$* * *$

Margarita (o cualquier bonita),

Hija del corregidor,

No te pongas tantos novios, 22

Que ya tu padre murió. ${ }^{23}$

[Esperanza Hernández Tejera, 29 de agosto, 2009]

${ }^{20}$ Esta bamba pertenece a los que López Sánchez denomina como "Bambas de piropos" (López Sánchez 2003: 118).

${ }^{21}$ Luis Sánchez documenta una versión de Albaida, donde la niña deja caer un volante, y es el novio quien lo recoge: La niña que está en la bamba/ se le ha caído el volante/ quién lo vino a recoger/ su novio que está delante" (López Sánchez 2003: 100). La canción parece una versión de otra anterior: "A una niña en la Carrera/ se le cayó el abanico/ y fueron a recogerlo/ entre cuatro señoritos" (Cancionero 185: 386). Dicha canción se relaciona además con el conocido motivo de las tres morillas que van a recoger olivas "y hallábanlas cogidas".

22 Aquilino Duque (79 años): "tantos moños"

${ }_{3}^{23}$ Margarita era la hija del Corregidor en la obra El Corregidor de Almagro de Manuel Fernández y González. En su relato La primera misa, el P. Luis Coloma explica del Corregidor de Almagro "que de puro meterse donde lo llamaban, se murió un día de pena, porque a su vecino se le quemó la olla" (Coloma 1884: 489). La canción aparece recogida también en Francisco Rodríguez Marín (Todavía 10.700 refranes más: $244 \mathrm{~b})$. 
Eres más chica que un huevo

Y ya te quieres casar. ${ }^{24}$

Corre a decirle a tu madre,

Que te enseñe a remendar

Los calzones de tu padre. ${ }^{25}$

[Rosario Avecedo, 84 años, 29 de agosto 20o9]

Mi madre me dijo a mí

Que cantara y no llorara,

Que echara las penas al aire

Mientras que yo me montara. ${ }^{26}$

[Rosario Avecedo, 84 años, 29 de agosto 20o9]

$* * *$

El día que yo nací,

Nacieron todas las flores.

Por eso me pusieron

María de los Dolores. ${ }^{27}$

[Rosario Avecedo, 84 años, 29 de agosto 20o9]

$* * *$

Tiene' una mala costumbre,

Que te tengo que reñir,

Que te quitas de mi puerta,

Cuando te me ves venir. ${ }^{28}$

[Rosario Avecedo, 84 años, 29 de agosto 20o9]

\section{LA ESPACIALIZACIÓN DE LA CALLE: LOS JUEGOS}

En un trabajo reciente sobre espacios de recreo, Heath Shenker destaca como los espacios urbanos se erigen en representación de la identidad colectiva. Frente al interés de la clase pudiente por mantener los espacios urbanos, los individuos con menos recursos habrían intentado transformar esos mismos lugares.

${ }^{24}$ La canción se recoge el en Cancionero popular de Priego (Alcalá 1984: 398 y 467).

25 En la tradición de Ubrique hay una canción que dice: "Eres más fea que un oso [eres más chica que un huevo]/y si te quieres casar/ más valdría que tu madre / te enseñara a remendar/ los calzones de tu padre" (Peña 2013: 138).

${ }_{26}$ C. Morán recoge una variante del último verso: "cuando de ti me acordara" (Morán 1954: 238).

27 López Sánchez recoge la misma canción en Aznalcázar (López Sánchez, 2003: 150).

${ }^{28}$ La versión recogida por Rodríguez Marín dice: "Tienes una mala maña/ que te la bengo (sic) a reñir; / que te quitas de la puerta/ cuando me bes de benir (sic)." (Cantos 1882: 44). 
Concebido como lugar de conflicto, el espacio urbano se prestaría a una serie de ritos y preparaciones destinados a afianzar la posición social de los diferentes individuos (Zumthor 1983: 267). A través del juego, los participantes se enfrentan a una obligación social por las que se abrogan o cuestionan las estructuras sociales. Mediante la actividad del juego, los participantes se integran en el espacio y reafirman su pertenencia al grupo social (Zumthor 1983: 93).

Como norma general, el juego facilita la transformación y creación de ciertas estructuras simbólicas que refuerzan el valor de religión o la historia reciente (Turner 1982: 58). A través de la utilización de recursos como la gradación la concatenación o la rima, los participantes descartan la posibilidad de una ruptura social y favorecen nuevas formas de comunicación y de asociación entre los diferentes miembros del grupo. Cuanto más naturales sean los procesos de cambio, tanto más efectivo será el resultado del juego. A medida que el cuerpo se localiza y se sitúa en el espacio conocido, el ritual genera diferentes nociones de jerarquía social que afectan la percepción del espacio. La organización jerárquica del espacio depende a su vez de una explicación verbal de cada canción de juego, donde la acción pasada se percibe como una acción que se repite ad infinitum.

En el caso de los juegos de escondite, la exploración de los niños utiliza el espacio para crear nuevas alianzas y para establecer nuevos límites territoriales (Piñero 1987; Droege 1977: 311). El uso del diálogo permite aquí presentar los sucesos al auditorio con el propósito de infundir un sentido de vitalidad (Piñero 1987: 46) y facilitar la intervención ritual de los diferentes participantes.

Los ejemplos son numerosos:

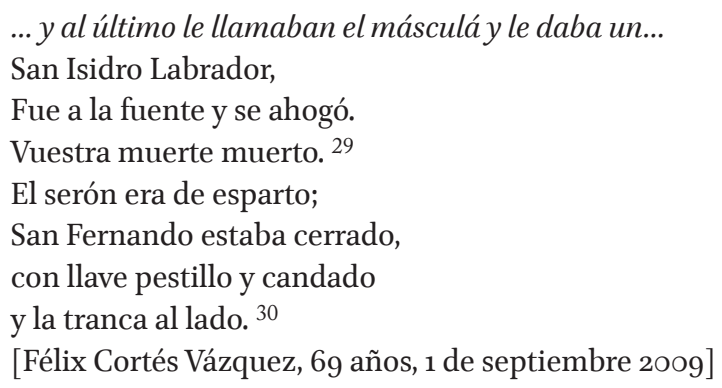

Cogíamos una piedra y el que la quedaba cerraba los ojos, porque los otros se encondían. Los que se escondían tenían que venir a cogerme el mollero pero yo estaba

\footnotetext{
29 Aquilino Duque (79 años): "Muerto lo llevan en un serón."

$3^{\circ}$ Miguel Ropero recoge una versión similar en Sevilla (Ropero 1987: 401). Se trata de una variante de la piola.
} 
pendiente: fulano está en tal sitio y le daba al mollero. Y si alguien se adelantaba decía: "arze el mollero por todos mis compañeros".

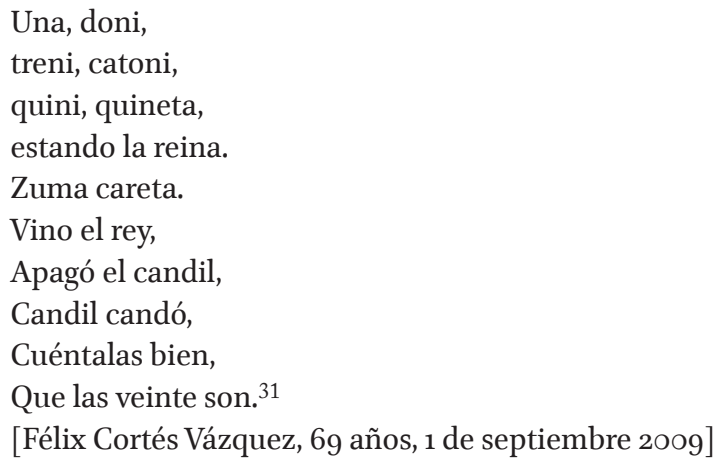

El coger: Se echaba número. Iba uno y se escondía y el grupo tenía que saber dónde estaba y cuando lo encontraban decían

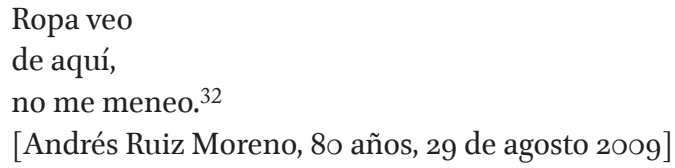

Al lobo. Te amarraban por aquí por la cintura una soga larga y tú eras el que había perdido y tenía que amarrarte y los otros decían... y soltaba el lobo pero amarra'o y cuando iba a tocar la persona tiraba de la soga y no podía:

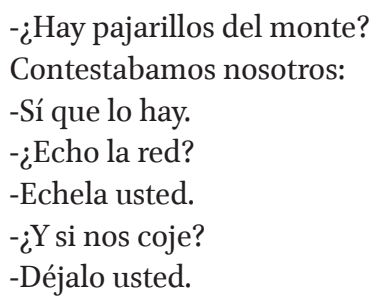

$3^{31}$ Existen numerosas variantes es esta canción. Según Alberto Sevilla, la canción se decía en el juego de las rayas (Sevilla, 1921: 38)

$3^{2}$ V. José Zorrilla: "Pues señor, de este lugar/ no me meneo aunque venga/ el diluvio universal" (1872: 367 ). 


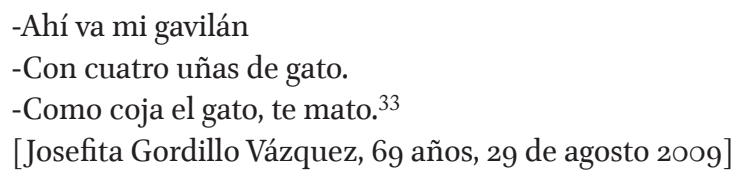

La idea de grupo social parece reforzada por la alusión directa a personas del entorno del niño que desempeñan un acto de poder. La alusión al abuelo en el siguiente juego debe entenderse como el recurso a un principio de poder, similar a la interjeción que se encuentra en las jarchas o en el Romance de don Bueso, donde la alocución se dirige a la madre:

Nos poníamos las chiquillas de la mano a tapar la calle:

A atajar la calle,

Que no pase nadie

Na más que mi abuelo,

Que si no me muero.

A atajar la calle,

Que no pase nadie,

Na más que mi abuelo.

Maravilla, maravilla,

Que me hinque de rodillas. ${ }^{34}$

[Esperanza Hernández Tejera, 71 años, 29 de agosto 20o9]

En otras ocasiones, se trata de la ritualización de una canción conocida. La historia de un matrimonio fallido se interpreta como una ritualización del pasado en un juego donde los niños adoptan diferentes personajes. El diálogo entre los diferentes participantes se ofrecía por su parte a una teatralidad que se mantiene en todas las representaciones del juego. Los diálogos sirven por otra parte para guiar las acciones del participante y adjudicarle un puesto dentro del juego. Estos diálogos pueden adoptar la forma de pregunta retórica, interpelación o simplemente frases que animan a los participantes a resolver el problema en cuestión:

-Soldadito soldadito,

De qué guerra viene usted

-De la guerra de Melilla

-¿Qué se la ha ofrecido a usted?

33 Existe un juego similar en "San José de las Matas" (República Dominicana). "Un rey pero con un ayudante al que le llaman gavilán y al rey padre, la otra parte del grupo sale a correr, cuando el padre dice mando a mi gavilán pollero con 7 uñas de gato si no me trae carne fresca te mato, el gavilán sale a capturar, el que agarre tendrá un castigo, si no logra agarrar a nadie el gavilán es el castigado. Los muchachos se liberan diciéndole padre al rey (Roberto Torres, 2015). Otra versión aparece en el cancionero de Valverde del Camino (Gómez Cera 1999).

34 La misma letra aparece recogida por Antonio Machado y Álvarez, con algunas variantes, proveniente de Zafra (Huelva). La explicación del juego es la misma (Machado 1884: 141-142). La letra aparece recogida en Rodríguez Marín (Cantos 1882: 54). 
Y contestaba otra:

- ¿Ha visto Vd. a mi marido

En la guerra alguna vez?

Mi marido es alto, rubio

Con sombrero cordobés

Y contestaba la otra:

-No señora, no lo he visto

Dice la señal que es

-Mi marido tiene un pañuelo bordado

Que yo se lo bordé,

Otro que le estoy bordando,

Y otro que le bordaré.

-Calla, calla Isabelita

Calla, calla, Isabel

Yo soy tu querido esposo

tú mi querida mujer. ${ }^{35}$

[Esperanza Hernández Tejera, 71 años, 29 de agosto 2009]

...y se cambiaba uno...

Piola y muda. ${ }^{36}$

[Félix Cortés Vázquez, 69 años, 1 de septiembre 20o9]

$* * *$

Run, run, run.

¿De quién es el ruido

¿Qué anda por ahi

Que de día y de noche

No nos deja dormir?

Somos la

Que venimos a estudiar.

De la capilla de la Virgen del Pilar

Con un mantón de oro ${ }^{37}$

35 Se trata de una versión del romancero "Señas del esposo", recogido en numerosas regiones (Fraile 1993: 27).

${ }^{36}$ Miguel Ropero recoge una versión similar en Sevilla (Encuentas 1987: 401). Refiriéndose al mismo juego en las islas Canarias, Fernando Marrero Pulido lo describe en los siguientes términos: "Todos los jugadores tenían que decir, en el momento del salto, "piola y muda". Caso de no hacerlo, el jugador infractor pasaba a sustituir al burro. En el segundo salto, el burro se retiraba a la distancia que marcara el primer jugador. Había que estar atento, pues, al salto del primer jugador. Si al tiempo de saltar daba un toque con el pie derecho al "trasero" del burro, todos los demás tenían que hacer lo mismo. Al tercer salto, el burro se colocaba más lejos, por lo que el juego se iba complicando al saltar, desde la raya trazada, hasta el burro" (Marrero 1998: 134).

37 Aquilino Duque (79 años): "Venimos de la capilla/ de la Virgen del Pilar." María Ángeles Bazalo y Raquel Benítez recogen una canción similar, con claros trazos tradicionales: “¿Qué es esa gente que

ISSN $1132-0265$

DOI 10.12795/PH2016.i3o.21

Philologia Hispalensis 30/2 (2016) 81-105 
Y otro de plata.

Que se quite

La de la puerta falsa. ${ }^{38}$

[Isabel Vázquez, 65 años, 30 de agosto 20o9; Félix Cortés Vázquez, 69 años, 1 de septiembre 2009]

La ritualización del encuentro entre la mujer y el hombre tiene uno de sus símbolos más claros en la aparición del pañuelo, elemento que la tradición identifica invariablemente con actos de unión sexual. La figura del bandolero o de un moro se presenta aquí como el elemento de peligro que otorga aún más dramatismo al contexto en el que se desarrolla el juego. La existencia de la calle confiere por otro lado al episodio un dinamismo y una dimensión pública que insiste en el aspecto ritual y que convierte a los participantes en el juego en cómplices y vigilantes de la nueva unión. Quien quiera que participe en el juego debe obedecer las normas establecidas por la letra misma, si bien se le permite adoptar el papel de vencedor o de perdedor. En este sentido, el diálogo no concluye el juego sino que lo reinicia, abriendo la posibilidad a nuevas responsabilidades dentro del grupo social. En el caso de la canción de corro, la canción se abría además al inicio de un baile por sevillanas.

Canción de corro. La del medio se lo iba poniendo a las del corro.

Ay qué calle tan bonita,

Ay qué oscuridad de calle,

Ay qué niña tan bonita,

Si me la diera su madre.

Este pañuelo de ronda,

Que del cielo se ha caido,

Lo ha cogido un bandolero,

Y yo lo ha ha (sic) recogido.

Así se lo pone el moro,

Así los bandoleros,

Así las niñas bonitas,

Y así se lo echa al cuello. ${ }^{39}$

[Félix Cortés Vázquez, 69 años, 1 de septiembre 20o9]

pasa por aquí?/ Ni de día ni de noche/ me deja dormir./ Son los hijos del rey moro que vienen por doña Ana./ Doña Ana no está en casa, que está en el jardín, / abriendo la rosa cerrando el jardín." (Bazalo 2005, p. 1197).

$3^{8}$ La misma canción existe, con algunas variantes, en la región de Murcia. (Martín Escobar 2009: $682)$.

39 La canción aparece, con algunas variantes, en una tradición de Jaén (Linares 2005: 63). 


\author{
Con esos tirabuzones \\ Que te cuelgan por la cara \\ Parece' una Magdalena \\ Cuando por el mundo andaba. ${ }^{40}$ \\ Que ay ay ay ay la ganá, \\ Que ay ay ay ay tócate, \\ Que ay ay ay ay la ganá, \\ Qué carrera será. \\ ...y empezaba una sevillana... \\ [Félix Cortés Vázquez, 69 años, 1 de septiembre 20o9]
}

\title{
3.1. COPLAS DE ESCARNio
}

Las canciones de escarnio se dirigen principalmente hacia aquellos que no forman parte del entorno y constituyen en su inmensa mayoría adaptaciones de canciones de escarnio anteriores, referidas a otras poblaciones. Las canciones de escarnio tienden a afirmar los valores del grupo social y a reconocer aquellas condiciones que permiten identificar a los forasteros. Entendidas como medio de interpelación, las canciones de escarnio se asocian a la violencia y la agresión. En tanto que formas de insulto, las coplas de escarnio constituyen "una acción verbal y/o no verbal, sancionada como ofensiva, cuyas unidades léxicas pueden o no representar en sí mismas una carga insultante al evocar conceptos sociales convenidos para ello" (Colín 2005: 32). La contraposición entre el pasado y el presente lleva por otro lado a lo que Lauri Honko reconoce como una fusión de espacio y tiempo propia de las canciones épicas. Al igual que en este tipo de canciones, las coplas de escarnio se resuelven en una especie de atemporalidad donde el pasado se repite constantemente (Zumthor 1983: 157).

La manipulación social que se produce en las coplas de escarnio tiende a establecer un paradigma de acción donde el pasado ideal se opone a un presente degradado, cuya ruina conviene evitar a toda costa. La visión de un Bormujos feo se opone a la belleza de sus mujeres, y el enfado de los habitantes de Castilleja de la Cuesta contrasta con el orgullo de Bormujos, quien entre 1945 y $195^{2}$ tuvo su propia feria de ganado, gracias a los trabajos del alcalde José Luis Piñal Escobar. La división temporal del pueblo se sobrepone a una visión espacial que permite la libre acción de los habitantes y les da pie a expresar sus ideas.

Las diferentes canciones de escarnio se organizan a lo largo de la calle principal del pueblo y de la carretera hasta Sevilla. Ya en el siglo XX gran parte de la población acostumbraba a recorrer los escasos seis kilómetros que los separaban de la Pañoleta, y ahí tomaban el tranvía que los llevaba hasta Sevilla. Gran parte del

40 V. Cancionero popular de Priego (Alcalá 1991: 748). Cf. Cancionero popular (1865, p 63): "Con esos rizos hermosos/ Que te cuelgan por la cara/ Pareces la Magdalena,/ Cuando por el mundo andaba." 
pueblo se hallaba empleada en los almacenes de aceitunas: el Inglés, que estaba en la calle San Jacinto y la Exportadora, que estaba en la Avenida de Manuel Siurot. Salían de madrugada, y trabajaban media jornada. ${ }^{41}$ Para llegar a la Pañoleta, los trabajadores tenían que cruzar Castilleja de la Cuesta y bajar hasta la Pañoleta, donde se subían al tranvía:

Dice que Bormujo' es feo

Porque no tiene balcones,

Pero tiene unas mocitas

Que parten los corazones. ${ }^{42}$

[Félix Cortés Vázquez, 69 años, 1 de septiembre 2009]

$* * *$

Se está poniendo Bormujos

A estilo de capital,

Con los zapatos de tanque

Y las medias de cristal;

Los viejos con las corbatas

Y las viejas ondulás. ${ }^{43}$

[Félix Cortés Vázquez, 69 años, 1 de septiembre 20o9]

$* * *$

Esto es una sevillana muy antigua:

La gente de Castilleja

Está que emberrea (sic),

Porque quiere una feria

Y no se la dejan.

[Isabel Vázquez, 65 años, 1 de septiembre 20o9]

$* * *$

Cuando pasaban las mujeres que iban a la Exportadora iban las mujeres andando por la trocha. Ycuando venían se lo decíamos y nos insultaban de vuelta:

${ }^{41}$ Uno de los informantes, Félix Cortés Vázquez, bromea con el caso de una mujer que a ir al trabajo, junto al palacio de San Telmo, vio varias figuras en lo alto y les dijo a sus acompañantes: "vamos ligero, que esos hombres están trabajando ya."

42 López Sánchez recoge una letra similar referida a Aznalcázar (López Sánchez 2003: 127).

43 Una copla similar se recoge en Aznalcázar. (López Sánchez 2003: 151). Aquilino Duque (79 años) recoge una copla que dice: "Dicen que Coruña es fea/ porque no tiene balcones/ pero tiene unas rapazas / que roban los corazones."

ISSN $1132-0265$

DOI 10.12795/PH2016.i3o.21

Philologia Hispalensis 30/2 (2016) 81-105 
Castilleja está en un cerro

Y Bormujos en un valle.

Por eso Espartinas

Tiene una calle. ${ }^{44}$

[Dolores Polvillo Veloso, 63 años, 29 de agosto 2009]

$$
* * *
$$

Al entrar por Castilleja,
Lo primero que se ve:
Los balcones abiertos
Y las camas sin hacer. ${ }^{45}$

[Dolores Polvillo Veloso, 63 años, 29 de agosto 2009]

$$
* * *
$$

El pueblo estaba separado en dos partes. Las del barrio de Arriba íbamos a meternos con las que vivían en las Cochineras, cerca del Cañón. El pueblo se dividía por aquella época en dos partes: la Cruzy Maclica.

Las del barrio de arriba

Gastan muchas tonterías,

Zapatos de cinco duros

Y las barrigas vacías. ${ }^{46}$

[Carmen Vargas, 82 años, 29 de agosto 20o9]

$$
* * *
$$

Eres más chica que un huevo, más negra que una morcilla Y te quieres poner blanca

A fuerza de mantequilla ${ }^{47}$

[Félix Cortés Vázquez, 69 años, 1 septiembre 20o9]

44 En Orellana (Cáceres) se canta una jota que dice: "Orellana está en un cerro/ Orellanita en un valle/ Y la pobre de Acedera/ No tiene más que una calle" (Pellecín 1981: 147).

45 Existen numerosas versiones de esta canción atribuidas a Caravaca (Vivo 2003: 110). Cf. María del Pilar Cruz Herrera (1993),

${ }^{46}$ La canción parece adaptada de una murga de Higuera la Real (Badajoz) que dice: "Higuera ya no es la Higuera/ que es una gran capital/ y los trajes de astracán/ puestos los llevan ya./Hay algunas presumidas/suelen llevarlo de pelo/ resulta que a los tres meses/ se lo deben al tendero./ Las muchachas de hoy en día/gastan mucha fantasía:/zapatos de a cinco duros/ y la barriga vacía./Zapatos de a cinco duros y la barriga vacía./ Luego se van a los bailes/con faldas de terciopelo;/no saben cómo peinarse/ todas se cortan el pelo./ Las muchachas de hoy en día/ nos causan admiración;/la falda por la rodilla/ y el peinado a lo garzón. /La falda por la rodilla y el peinado a lo garzón." López Fuentes (30 agosto 2012).

47 La misma canción se canta en Benacazón (López Sánchez 2003: 177). 
Como norma general, las canciones facilitan una reclasificación de las estructuras sociales que se refleja también en las invectivas personales. La figura del cofrade que pierde los dientes o del burro que no tiene herraduras apuntan a las carencias sociales de los diferentes personajes que se ven excluidos del grupo y que se convierten en arquetipos sociales, y en ejemplos negativos de la comunidad. En este tipo de canciones, la pobreza se concibe como una forma extrema de segregación. El hombre que ha perdido todo su haber o el padre que no tiene dinero para pagar las herraduras del borrico se convierten en objeto de burla. En este caso, el insulto se refiere no ya a los infortunios del individuo sino de las malas condiciones que lo han llevado a esa situación.

Perico era uno de la hermandad que robó mucho dinero.

El pobrecito Perico

De tanto como ha sufrido

Con esto de la hermandad

Hasta los dientes ha perdido.

El pobre Perico

Llamaba a su madre:

"Tráeme una silla

Que voy pa' la cárcel."

[Félix Cortés Vázquez, 69 años, 1 de septiembre 20o9]

$* * *$

Tu padre tiene un borrico

Que no tiene jerraúra

Cuando va andando va soltando

...una palabrota ...

[Félix Cortés Vázquez, 69 años, 1 de septiembre 20o9]

\subsection{CANCIONES DE FAENA}

Hasta época reciente, la economía de Bormujos ha sido eminentemente agraria. En el núcleo urbano de Bormujos existían cuatro grandes haciendas: la hacienda de Marchalomar ${ }^{48}$, la de Belén (fundada en el siglo XVIII), la de Nuestra Señora del Rosario o la Pelegrina (fundada en 1759) y Valencinilla del Hoyo. A estas se unían la de El Santo Cristo de la Mata (1612), La Hacienda de Valencinilla del Hoyo (Rosa 115).

${ }^{48}$ La hacienda de Marchalomar formaba parte del mayorazgo de Juan Antonio del Alcázar en 1578 (Matute 1886: 415). 
En 1921, Alfonso XIII visitó la hacienda de la Pelegrina para examinar unos tractores CLETRAC que D. Manuel Piñal había traído a la finca. ${ }^{49}$

Uno de los informantes, Félix Cortés Vázquez, recuerda que la mayoría de los cultivos del pueblo eran de tierra calma, y que el trigo se plantaba entre los olivos. Para la década de 1950 existían eras particulares y eras comunales. Las eras que recuerda eran: la de la Pelegrina (en la carretera de Mairena), la de Marchalomar (en la carretera de Gines), la del Quiqui, la de Alfonso Chepa (situada junto a la iglesia), la de Valencinilla del Hoyo (en un cerro de la vereda de la Carne), la del Banquillo, la del Pequeño y la de Margarita, (que estaba detrás de la iglesia llamada así por Margarita Gaviño Morillo) ${ }^{50}$ y la de Ignacio (junto al cementerio).

Dentro de las canciones de faena, Pilar Montero Curiel distingue dos tipos: aquellas que "contienen marcas léxicas y temáticas relacionadas con las tareas del campo" y aquellas que, "sin proporcionar siempre esas referencias, se adaptan al contexto cultural de las labores rurales y se interpretan en su marco". ${ }^{51}$ Mientras que los fandangos solían cantarse durante la recogida de aceituna (Félix Cortés Velázquez, 69 años), la trilla parece haberse especializado en la cuarteta octosílaba. La materia es en la mayoría de los casos amorosa (López Sánchez 2012: 5), si bien las canciones tienden a dirigirse a la audiencia, ya sean las mulas o las personas que rodean al trillero. La regularidad métrica de este tipo de canciones se prestaba por otro lado a una serie de repeticiones que, al igual que otras canciones de faena, tendían a medir el tiempo de manera más o menos constante (Nagy 1976: 239). Así al menos se desprende de las diferentes versiones de los cantes de la era o de las numerosas interjecciones que puntúan el tiempo de la canción de trilla (García Martín 1989). Se explica que el nombre "la era Margarita" aparezca a veces como "la era Baldomero", en un esfuerzo por adaptar la tradición a su propia experiencia personal.

La imagen de una yegua que encuentra placer en comerse el trigo que trilla, la visión de un hombre que siembra piñones y descubre calabazas (o soldados), la presencia de un portugués, sugieren un doble sentido no exento de humor donde la trilla evoca diferentes episodios del cortejo y donde la mujer a veces se compara con la mula.

Los niños se solían sentar en el trillo para hacer peso durante la trilla. El hombre iba montado en el borrico, iba trillando y cantando a la vez. Porque cuando daba el trillo la primera vuelta había que volver la paja. Lo llamaban aventar.

¡Andale ei!

49 Pineda Novo, inexplicablemente, da como fecha de la visita el año 1928 (Pineda 1978: 25). ABC, 11 marzo 1921.

5o Margarita Gaviño Morillo estaba casada con Gómez que fue capataz de obras públicas, responsable del asfaltado de la carretera de Villamanrique (Baldomero Gaviño, 69 años).

51 Montero 1995: 306. 
Esta ca'lunanca ${ }^{52}$

Le gusta el trigo,

$\mathrm{Y}$ despues viene el amo

riñe conmigo.

¡Andale ei!

[Félix Cortés Vázquez, 69 años, 1 de septiembre 20o9]

$$
* * *
$$

En la era Margarita

Sembré piñones,

Nacieron calabazas,

Cogí melones.

¡Hala, mula! 53

[Isabel Vázquez, 65 años, 30 de agosto 20o9]

$$
* * *
$$

En la era Margarita,

Hay un portugués,

A voces viene diciendo,

Vamos a volver. ${ }^{54}$

Ale.

[Alfonso Gaviño, 69 años, 15 de julio 2011]

$$
* * *
$$

Esta noche ha llovido,

Mañana hay barro.

Cuatro mulitas tordas

Lleva mi carro. ${ }^{55}$

[Andrés Ruiz Moreno, 8o años, 29 de agosto 20o9]

\footnotetext{
$* * *$

$5^{2}$ Aquilino Duque (79 años): "A esta mula lunanca." "Lunanca", se dice de la yegua que tiene un anca más alta que la otra.

53 La revista El Padre Cobos recoge en 1855 una letra similar: "A la vera de un río/sembré piñones/ salieron calabazas/y calabazones" (20 de marzo de 1855). Otra versión recogida por Emilio Abreu Gómez dice: “A orilla del río/sembré piñones/y salieron muchachos/con pantalones!”(Abreu 1951: 184)

54 La figura del portugués aparece en el teatro breve del XVII como epitome de vanidad y arrogancia (Borrego 2015).

55 Esta canción figura entre otros en el cancionero leonés donde una moza asomada en un balcón se gana una admonición para evitar habladurías (Cabañas 2002: 124).
} 
Por ahí la muerte,

Me quiere llevar.

$\mathrm{Al}$ entierro lo llevan

Los cigarrones. ${ }^{56}$

[Andrés Ruiz Moreno, 8o años, 29 de agosto 20o9]

La transmisión de las canciones populares en un pueblo del Aljarafe sevillano evidencia el complejo entramado de préstamos y de motivos que cambian no sólo de un barrio a otro sino también de un individuo a otro. Independientemente del peso de la tradición, los diferentes informantes expresan la importancia que las canciones tienen a la hora de definir el espacio físico y social del pueblo. No en vano, es a partir de la explicación de las canciones que los informantes organizan sus recuerdos sobre la escuela, el trabajo o las tradiciones locales. En este sentido, las diferentes canciones permiten llevar a cabo lo que Bauman define como una segmentación del recuerdo, una división del material folklórico en diferentes unidades discretas que permiten no sólo la transmisión sino la recreación de ese legado (Bauman 1971: 32 ).

La mayor parte de las relaciones sociales que tienen lugar en las canciones ocurre en un espacio físico donde los diferentes habitantes buscan entretenimiento y donde se consolidan los símbolos de estado social y de identidad (Honko 1986: 19-20). Las diferentes tramas que se reflejan en las canciones, las improvisaciones ocasionales, resultan en una confusión. Lejos de proponer una solución normativa y social al contenido de las canciones, la representación y la explicación que de ellas se hace genera una serie de problemas que la comunidad debe resolver, a menudo de forma contradictoria. Las quejas sobre la "juventud de hoy en día" o sobre la pérdida de las costumbres locales es un motivo constante dentro de las explicaciones que los informantes hacen de las canciones.

La hermosura de las mujeres se contrapone a la autoridad de las madres o de los abuelos y establece un nuevo paradigma de oposición que ve en la figura del amado un elemento de liberación, la sustitución posible del poder familiar por un nuevo lazo. Claramente, esta caracterización no se presta a un ejercicio de nostalgia. El interés de las canciones en expresar un momento de felicidad destaca la serie de comportamientos y de errores que llevaron a una degradación del momento presente. Dentro de esta oposición, el carácter lúdico del centro del pueblo, las diferentes ventas y corrales, se contrapone a la violencia que se genera en los límites fronterizos e invita a los personajes a buscar la seguridad del grupo social (Zumthor 1983: 273). Es en este reconocimiento del espacio físico y moral donde los diferentes informantes buscan lo que Richard Bauman reconoce como un código lingüístico compartido (Bauman 1981: 41).

${ }^{5} 6$ Posiblemente se trate de una canción de carnaval. Los cigarrones son unos personajes enmascarados que figuran en el Carnaval de Verín, de Galicia. 


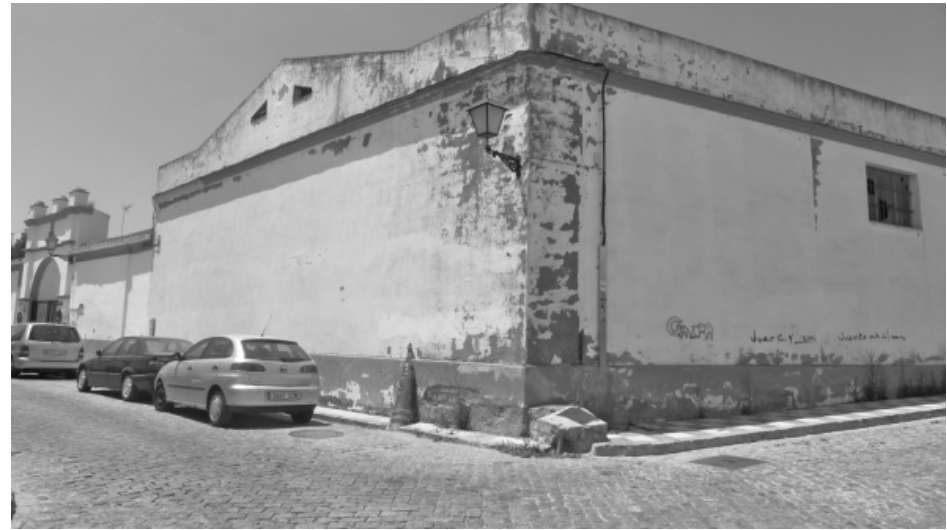

Figura 2. La plaza del cañón (Bormujos). Colección del autor.

\section{BIBLIOGRAFÍA}

Abreu Gómez, Ermilo (1951): Naufragio de indios. Ciudad de México: Ediciones Botas. Alcalá Ortiz, Enrique (ed.) (1984-1991): Cancionero popular de Priego: poesía cordobesa de cante y baile. Priego: Excmo. Ayuntamiento.

Alonso Cortés, Narciso (1914): "Cantares populares de Castilla", Revue hispanique 32, $87-427$.

ANTEQuera Luengo, Juan José (2010): En torno al topónimo arábigo Bormujos. Sevilla: Facediciones.

BAUMAN, Richard (1971): "Differential Identity and the Social Base of Folklore", Journal of American Folklore 84, 31-41.

BazAlo Miguel, María Ángeles/ Benítez Burraco, Raquel (2005): "El romancero de la tradición moderna en Carmona", Carel 3(3), 1187-1246.

Воно́rQuez, Manuel (2000): La Niña de los Peines en la casa de los Pavón. Sevilla: Signatura. BORREGO, Esther (2015): "Portugal y los portugueses en el teatro cómico breve del siglo XVII: de los entremeses a los villancicos", Hipogrifo 3 (2), 49-69.

Cabañas Alamán, Fernando J. (ed.) (2002): Cancionero musical de Castilla. Cuenca: Universidad de Castilla la Mancha.

CADENas Vicent, Vicente (1993): Caballeros de la Orden de Santiago que efectuaron sus pruebas de ingreso durante el siglo XIX. Madrid: Hidalguía.

CoLÍn RodeA, Marisela (2005): "Modelo interpretativo para el estudio del insulto", Estudios de lingüística aplicada 23(41), 13-37.

Coloma, Luis (1984): "La primera misa”, en: Obras completas. Vol. 2. Bilbao: Mensajero del Corazón de Jesús.

Cruz Herrera, María del Pilar (1993): "Diccionario de gentilicios y seudogentilicios de la provincial de Albacete", Zahora 42, 7-168.

Droege, Peter (1997): Intelligent Environments: Spatial Aspects of the Information Revolution. Amsterdam: Elsevier. 
DuRÁn Medina, Carmen (1999): “El Cancionerillo de Aznalcázar. Aproximación a la bamba”, en: Pedro Piñero, Enrique Baltanás/ Castellano, J. Pérez (eds.): Romances y Canciones en la Tradición Andaluza. Sevilla: Fundación Machado, 169-19o.

FERNÁNDEZ GonZÁLEZ, Manuel (1871): El corregidor de Almagro. Madrid: J. Graciá.

Fernández Molina, Lorenzo, "Así habla y canta mi pueblo Moral de Calatrava”.

Disponible en: http://www.elmoraldecalatrava.com/hablaycanta.pdf. (o5 junio 2016).

FinNegan, Ruth (1977): Oral Poetry. Its nature, Significance and Social Context. Cambridge: Cambridge University Press.

FoleY, John (2002): How to Read an Oral Poem. Urbana and Chicago: University of Illinois Press.

Fraile Gil, José Manuel (1993): “Un muestreo en la poesía tradicional de La Mancha baja”, Zahora 33, 45-57.

GARCía MARTín, José María (1989): “Algunos aspectos formales del vocativo en el romancero Viejo”, en: Piñero, Pedro/Atero, Virtudes / Rodríguez Baltanás, Enrique J./ Ruiz, María Jesús (eds.): El Romancero. Tradición y pervivencia a fines del siglo XX. Sevilla: Fundación Machado, 279-302.

García MercadAL, Juan (1966): El Humor en la prensa española. Madrid: Taurus.

GómEz CERA, Manuel Fernando (1999): "Juegos y canciones de Valverde”, Revista de Folklore $19 \mathrm{~b}(225), 94-96$.

Guerra Garrido, Raúl (2001): Miento, Madrid: Huerga y Fierro.

Guerrero Ruiz, Pedro/López Valero, Armando (eds.) (1996): Poesía popular murciana. Murcia: Universidad de Murcia.

GuNNELL, Terry (2006): "Narratives, Space and Drama: Essential Spatial Aspects Involved in the Performance and Reception of Oral Narrative", Folklore 33, 7-26.

Gutierre De Cetina (1895): Obras. Sevilla: Francisco de Paula Díaz, 126-140.

Gutiérrez Padial, Juan (1982): Lanjarón, historia y tradición, Monachil (Granada): Editorial Santa Rita.

Herrera García, Antonio (1991): "Un amojonamiento del término de Bormujos en 1631", Boletín de la Real Academia Sevillana de Buenas Letras 19, 35-63.

Honko, Lauri (2013): Theoretical milestones. Selected writings of Lauri Honko. Edición de Pekka Hakamies / Anneli Honko. Helsinki: Academia Scientiarum Fennica.

Honko, Lauri (200o): “Text as Process and Practice”, en: Lauri Honko (ed.): Textualization of Oral Epics. Berlin: De Gruyter, 3-54.

Honko, Lauri (1986): "Studies on Traditions and Cultural Identity: an Introduction", ARV: Scandinavian Yearbook of Foklore 42, 7-26.

Honko, Lauri (1990): Religion, Myth, and Folklore in the World's Epics. Berlin: Gruyter.

Huizinga, Johan (1949): Homo Ludens: A Study of the Play-Element in Culture. London: Routledge \& Kegan Paul Ltd.

Lafuente Alcántara, Emilio (eds.) (1865): Cancionero Popular. París: J. B. Ballière e hijo.

LAPESA, Rafael (1968): Historia de la lengua española: Español medieval. Madrid: Escelicer.

López RuIz, Luis (2009): Guía del flamenco. Madrid: Akal.

LóPez SÁnCHEz, José Pedro (2003): Las coplas de bamba. Fiesta y canción. Sevilla: Sociedad de desarrollo local de Bollullos de la Mitación. 
LóPEZ SÁNCHEZ, José Pedro (2012):"Las canciones de trilla en el aljarafe sevillano", Olivar 18, 277-294.

LinARES LuCENA, Francisco A. (2005): El cancionero y folclor tradicional en Bailén. Bailén: Unicaja.

LóPez Fuentes, Juan Alfonso (2012): “Las murgas”. Disponible en: https://jeanfiguier. wordpress.com/2012/08/30/ (o6 junio 2016).

Macedonio Espinosa, Aurelio (1987): Cuentos populares de Castilla y León. Madrid: CSIC.

MACHADo Y Álvarez, Antonio (1884): Folk-lore español: Biblioteca de las tradiciones populares españolas. Sevilla: Alejandro Guichot y Compañía.

Marín Bañón, Susana/Carbajo Martínez, Concha (2009): Cancionero infantil de la Región de Murcia. Murcia: Consejería de educación.

Marrero Pulido, Fernando (1998): Raíces canarias. Arucas: Excmo. Ayuntamiento.

Martín Escobar, María Jesús/Carbajo Martínez, Concha (2009): Cancionero infantil de la región de Murcia. Murcia: Consejería de Educación.

MAXEY, James A. (2009): From Orality to Orality: A New Paradigm for Contextual Translation of the Bible. Eugene, Oregon: Cascade Books.

MATUte GAVIRIA, Justino (1886): Hijos de Sevilla señalados en santidad, letras, armas, artes o dignidad. Sevilla: El orden.

Montero Curiel, Pilar (1995) “Uso de la poesía popular”, AEF 18, 305-322.

MoRÁn BARDón, César (1954): “Refranes y sentencias populares”, Revista de dialectología y tradiciones populares $10(1 / 2), 228-248$.

MoYLAn, William (2012): "Considering Space in Record Music", en: Simon Zagorski-Thomas (ed.): The Art of Record Production: An Introductory Reader for a New Academic Field. New York: Routledge, 163-192.

NAGY, Gregory (1976): "Formula and Meter", en: Stolz, Benjamin A./Shannon, Richard S. (eds.): Oral Literature and the Formula. Ann Arbor: Center for the Coordination of Ancient and Modern Studies, 239-272

Palacio VAldÉs, Armando (1967): Los Majos de Cádiz. Madrid: Espasa Calpe.

Pedrosa, José Manuel/ Aguirre, María del Carmen/Gómez López, Nieves (2007): La voz del viento: Literatura tradicional recogida en la Cañada de San Urbano (Almería). Almería: Universidad de Almería.

Pellecín Lancharro, Manuel (1987): “La Extremadura que conoció Iliá Ehrenburg”, Revista de estudios extremeños 31 (1), 139-147.

Penna, Mario (1969): “Las Rimas de Bécquer y la poesía popular”, Revista de Filología Española 52, 187-215.

PeÑA DíAZ, Miguel Ángel (2013): Coplas de columpio de la tradición oral de Ubrique. Alcalá de Henares: Área de Teoría de la literatura y literatura comparada.

PÉREz, Ignacio (2005): Cuadernos de literatura de tradición oral 9. Disponible en: http:// www.anincat.org/wp-content/uploads/2012/10/Cuaderno-LitOral-9.-PRADO-DEL-REY1. pdf. (o6 junio2o16)

Pineda Novo, Daniel (1978): Historia de la Villa de Bormujos, Bormujos: Excmo. Ayuntamiento.

Ramnarine, Tina (2007): "Musical Performance in the Diaspora: Introduction", Ethnomusicology Forum 16, 1-17. 
PIÑERo, Pedro (2010): La niña y el mar. Formas, temas y motivos tradicionales en el cancionero hispánico moderno. Madrid: Iberoamericana.

PiÑERo, Pedro (1987): Romancero de la tradición moderna. Sevilla: Fundación Machado.

PiÑERo, Pedro (2004): "Lavar pañuelo / lavar camisa: formas y símbolos antiguos en canciones modernas, en: Piñero Ramírez, Pedro Manuel (ed.): De la canción de amor medieval a las soleares: profesor Manuel Alvar "in memorian". Actas del Congreso Internacional "Lyra minima oral III", Sevilla, 26-28 de noviembre de 2001, 481-498. Sevilla: Universidad de Sevilla.

RAYA, Andrés (2014): "Flamenco en mi memoria: a vueltas con las bamberas". Disponible en: http://memoriaflamenca.blogspot.com/2014/o3/a-vueltas-con-las-bamberas.html (o6 junio 2016)

RoDríGuez MARín, Francisco (1941): Todavía 10.700 refranes más. Madrid: Prensa española.

RodrígueZ MARÍN, Francisco (ed.) (1882): Cantos populares españoles, recogidos, ordenados e ilustrados. Sevilla: Francisco Álvarez.

Ropero, Miguel (1987): Encuestas del nivel popular. Sevilla: Universidad de Sevilla.

Rosa JimÉnEz, Carlos Jesús (2013): Transformaciones metropolitanas en el territorio cultural del Aljarafe sevillano. Tesis doctoral. Universidad de Sevilla.

Ruiz Fernández, María/ Fraile Gil, José Manuel/ Weich-Shahak, Susana (2008): Al vaivén del columpio: fiesta, coplas y ceremonial. Cádiz: Diputación de Cádiz.

SEvilla, Pedro (1921): Cancionero popular murciano. Murcia: Sucesores de Nogués.

SUÁREZ ÁlvAREZ, Luis (1989): "El romancero de los gitanos bajo andaluces, germen del cante flamenco", en: Piñero, Pedro/Atero, Virtudes/ Rodríguez Baltanás, Enrique J./ Ruiz, María Jesús (eds.): El Romancero. Tradición y pervivencia a fines del siglo XX. Sevilla: Fundación Machado, 563-624.

TorRES, Roberto (2016): "El rincón del arte matero". Disponible en: http://www. elrinconmatero.com/juegos_tradicionales.htm. (o6 junio 2016)

TURNER, Victor (1982): From Ritual to Theatre: The Human Seriousness of Play. New York: PAJ Publications.

Vivo Palomares, Gabriel (2003): "Literatura oral de la alta sierra", Anales de la Sierra de Segura 1, 105-114. Disponible en: http://www.asociacionsierradesegura.com/16Literatura oraldelaaltasierra.pdf. (o6 junio 2016)

Zorrilla, José (1852): “El diluvio”. Obras de José Zorilla. Tomo III. Paris: Baudry.

Zumthor, Paul (1983): Introduction à la poésie orale. Paris: Éditions du Seuil. 